\title{
Mesoporosity of Delignified Wood Investigated by Water Vapor Sorption
}

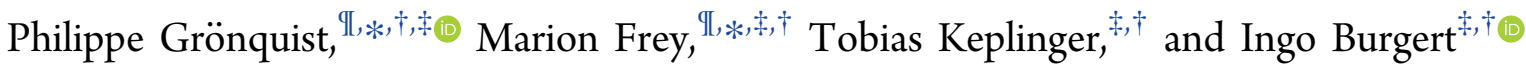 \\ ${ }^{\dagger}$ Laboratory for Cellulose \& Wood Materials, Empa, Überlandstrasse 129, 8600 Dübendorf, Switzerland \\ *Wood Materials Science, ETH Zurich, Stefano-Franscini-Platz 3, 8093 Zürich, Switzerland
}

Supporting Information
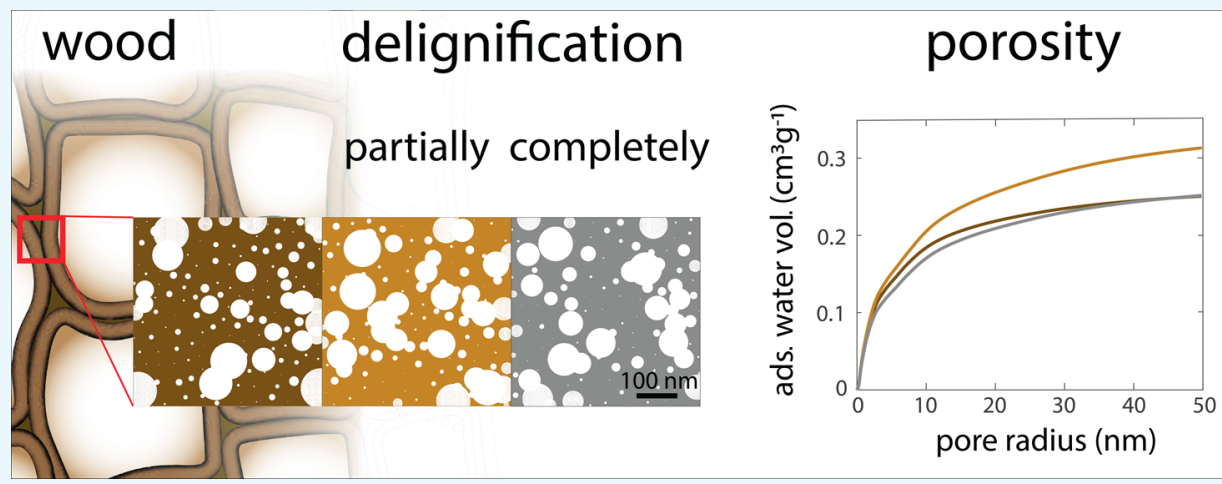

ABSTRACT: Wood represents a highly suitable biobased scaffold for the development of mechanically robust and functional materials. Its functionalizability can be enhanced by means of delignification, resulting in an increase in porosity due to partial or complete removal of lignin and hemicellulose constituents. In this work, the impact of partial and complete delignification on the mesoporous structure is investigated via water vapor sorption isotherms and deuterium exchange. Pore size distributions of wood samples with five different delignification levels were compared to native wood. The derived pore size distributions at the water swollen state reveal an increase in porosity with decreasing lignin content. However, after complete lignin removal, drying causes a nonreversible collapse of the cell wall, which results in reduced porosity.

\section{INTRODUCTION}

Delignification of wood is a common industrial process, which was recently re-suggested for innovative wood-based material developments. ${ }^{1-9}$ Hereby, the wood inherent cellulose scaffold is maintained, while part of the matrix components such as lignin and hemicelluloses are removed. These scaffolds can be functionalized $^{10,11}$ or infiltrated with various matrix systems $^{12-14}$ in both, dry and wet state. The investigation of cell wall porosity in the entire moisture content range is of high interest, as it determines the functionalizability.

Pore size distributions (PSDs) have been measured using various techniques. ${ }^{15}$ Mercury intrusion porosimetry is widely used to measure PSDs in the macroporous range $(>50 \mathrm{~nm}$ width). However, the technique is unsuited to characterize smaller pores within the cell wall. ${ }^{16,17}$ Thermoporometry by differential scanning calorimetry is an alternative but needs to be conducted at a low temperature $\left(-70{ }^{\circ} \mathrm{C}\right)$ in order to obtain a resolution in the nanometer range. ${ }^{18} \mathrm{~A}$ more precise characterization of micropores $(0-2 \mathrm{~nm}$ width) and mesopores (2-50 $\mathrm{nm}$ width) is provided by the use of gas adsorption isotherms. Nevertheless, the material is characterized in the dry state only and traditional $\mathrm{N}_{2}$ adsorption needs to be conducted at a low temperature $\left(<-196{ }^{\circ} \mathrm{C}\right)$, which potentially affects the material's microstructure. The characterization of pores by gas adsorption is very specific to the adsorbate molecule (e.g., its size, polarity), and its interaction with the adsorbent's surface. Therefore, derived values such as specific surface area or porosity need to be interpreted accordingly.

In the case of wood, the described methods do not capture swelling of the lignocellulosic polymers in the wood cell wall, which heavily impacts porosity. A suitable way of addressing this limitation is to characterize the pores of the wood cell wall at room temperature by water vapor sorption isotherms. The small and polar water molecule is able to penetrate narrow voids and is uniquely able to swell the wood cell wall. In contrast to traditional gas adsorption techniques, water vapor adsorption provides a structural analysis over the entire moisture content range by adsorption and subsequent desorption reaching a maximum partial pressure $\left(p / p_{0}\right)$ of 0.98. Additionally, the fully swollen state can be depicted when starting with desorption from the water-saturated state $\left(p / p_{0}=\right.$ 1 ). Water adsorption studies characterizing delignified wood or other natural cellulosic fibers are still relatively sparse, ${ }^{19-24}$ and

Received: March 28, 2019

Accepted: July 2, 2019

Published: July 22, 2019 
porosity changes upon delignification have not yet been investigated with this technique.

In this study, water affinity and cell wall porosity of native, partially, and totally delignified wood (Norway spruce) are characterized by means of water vapor sorption isotherms. PSDs are derived from isotherms starting at the dry and at the water-saturated state. The measurements are complemented by heavy-water deuteration experiments, which represent an additional way to characterize water vapor interaction. ${ }^{25-29}$ Deuteration of the material provides the number of available $\mathrm{OH}$ groups, which is an important factor for functionalization treatments.

\section{THEORY}

2.1. Assumptions on the Determination of the PSD. The Norway spruce earlywood cell wall is approximately composed of $48 \%$ cellulose and $52 \%$ matrix material $(21 \%$ hemicelluloses and $31 \%$ lignin). ${ }^{30}$ Cellulose chains form microfibrils of $2.5-3 \mathrm{~nm}$ in diameter, which means that only the $\mathrm{OH}$ groups on the surface of the microfibrils are accessible for water. Multiple microfibrils are arranged in bundles to form macrofibrils, which are embedded in the matrix material. ${ }^{31-34}$ By the current understanding, water molecules spontaneously and randomly adsorb on local sorption sites by forming hydrogen bonds with available $\mathrm{OH}$ groups of the polymers. The binding energy of this type of localized adsorption (26 kJ $\left.\mathrm{mol}^{-1}\right)^{35}$ lies in between physisorption (van der Waals interactions, $<4 \mathrm{~kJ} \mathrm{~mol}^{-1}$ ) and chemisorption (dissociative interactions, $\left.>50 \mathrm{~kJ} \mathrm{~mol}^{-1}\right)$. It can be expected that by increasing the partial pressure $\left(p / p_{0}\right)$, the locally available sites get occupied and capillary condensation takes place in larger voids or pores within the cell wall or middle lamella, predominantly in the mesopore range and above. ${ }^{36}$ However, water sorption mechanisms of wood or lignocellulosic materials are still largely unknown and are subject of current research and discussion. ${ }^{37-39}$

Hereafter, the common interpretation of a type IV IUPAC isotherm is assumed in order to derive the PSD from water sorption data. First, a multilayer physisorption mechanism at lower $p / p_{0}$ followed by a capillary condensation mechanism in mesopores is presumed. For simplicity, it is also assumed that the material possesses cylindrically shaped pores of radius $r$ and both, film volume and condensed volume simultaneously fill the pores. A model-less method to obtain properties of the first physisorption-alike mechanism is to consider the change in Gibbs free energy by adsorption $\left(\Delta G_{\mathrm{a}}\right)$. This value represents a change in surface energy, which characterizes the exothermic spontaneity of an adsorption process. ${ }^{40}$ It has already been used to analyze water adsorption on lignocellulosic materials. ${ }^{4-43}$ The interpretation of full water coverage, or an equivalent monolayer, at the maximum energetic adsorbate-adsorbent interaction state is often applied to materials such as porous silica, ${ }^{44}$ and PSDs derived from water adsorption were validated against PSDs from $\mathrm{N}_{2}$ adsorption. ${ }^{45}$ The maximum interaction capacity is used to correct the pore radius by assuming a water film thickness on the inner pore walls. However, in lignocellulosic materials, an existence of an equivalent monolayer capacity remains speculative.

2.2. Calculation of the PSD. 2.2.1. Adsorbed Film. In an adsorbent-adsorbate system, where $n_{\mathrm{a}}$ particles of the adsorbate are added as an ideal solution with chemical potential $\mu$ at partial pressure $p / p_{0}$, the change in Gibbs free energy of adsorption is defined as

$$
\Delta G_{\mathrm{a}}=n_{\mathrm{a}} \mu=n_{\mathrm{a}} R T \ln \left(p / p_{0}\right)
$$

where $R$ represents the molar gas constant and $T$ is the temperature. A plot of $\Delta G_{\mathrm{a}}$ versus $n_{\mathrm{a}}$ is shown in the Supporting Information (Figure S1) for the samples that are investigated in this study. At a certain amount $n_{\mathrm{c}}^{\Delta G}$, the exothermic process of adsorption is characterized by a maximum adsorbent-adsorbate energetic interaction. This amount can be calculated from analytical isotherm curves by using the condition

$$
n_{\mathrm{c}}^{\Delta G} \in\left\{n_{\mathrm{a}} \mid \frac{\mathrm{d}\left(\Delta G_{\mathrm{a}}\right)}{\mathrm{d} n_{\mathrm{a}}}=0, n_{\mathrm{a}}>0, p / p_{0}<1\right\}
$$

Calculated values of $n_{\mathrm{c}}^{\Delta G}$ for the investigated samples are compared in the Supporting Information S2 to values obtained when applying the more widespread but often criticized Brunauer-Emmett-Teller (BET) theory. At each amount $n_{\mathrm{a}}$, a theoretical film thickness on the inner pore walls can now be calculated as

$$
t=\frac{n_{\mathrm{a}}}{n_{\mathrm{c}}^{\Delta G}} \tau
$$

where $\tau$ is the thickness of a single layer of adsorbate $\left(\tau_{\mathrm{H}_{2} \mathrm{O}}=\right.$ $0.24 \mathrm{~nm})$.

2.2.2. Capillary Condensation. By assuming capillary condensation (in adsorption) and evaporation (in desorption) in cylindrical pores and under the assumption that the work against interfacial tension is equal to $\Delta G_{a}$, the Kelvin radius is defined as

$$
r_{\mathrm{K}}=\frac{-2 \gamma V_{\mathrm{m}} \cos \vartheta}{R T \ln \left(p / p_{0}\right)}
$$

where $\gamma$ is the surface tension $\left(\gamma_{\mathrm{H}_{2} \mathrm{O}, 25^{\circ} \mathrm{C}}=0.07197 \mathrm{~N} \mathrm{~m}^{-1}\right), V_{\mathrm{m}}$ is the molar volume, and $\vartheta$ is the wetting angle. It is assumed here that $\gamma$ does not change in dependence of $r$ and $\cos \vartheta=1$ (complete wetting of a plane solid surface).

2.2.3. Pore Volume Distribution. The pore radius as a function of $n_{\mathrm{a}}$ and $p / p_{0}$ can be obtained by adding the Kelvin radius to the film thickness as $r=r_{\mathrm{K}}+t$, and the adsorbed volume of water can be calculated from an experimental isotherm with

$$
V_{\mathrm{a}}=\frac{n_{\mathrm{a}} M_{\mathrm{H}_{2} \mathrm{O}}}{\rho}
$$

The density of condensed water $\rho$ is assumed here to be equal to the liquid density $\left(\rho_{\mathrm{H}_{2} \mathrm{O}}=1 \mathrm{~g} \mathrm{~cm}^{-3}\right)$, and the molar mass is $M_{\mathrm{H}_{2} \mathrm{O}}=V_{\mathrm{m}} \rho_{\mathrm{H}_{2} \mathrm{O}}=18.01528 \mathrm{~g} \mathrm{~mol}^{-1}$. The PSD, or pore volume distribution $\left(f_{\mathrm{V}}\right)$, follows by solving the generalized adsorption equation ${ }^{45,46}$

$$
V_{\mathrm{a}}=\int V_{\mathrm{M}} f_{\mathrm{V}} \mathrm{d} r
$$

$V_{\mathrm{M}}$ represents a dimensionless model isotherm for pore filling according to the specific assumptions made on the pore shape. An approximate analytical formulation ${ }^{47}$ for the PSD can be given by the expression

$$
f_{\mathrm{V}}=\left(\frac{r}{r-t}\right)^{2} \frac{\mathrm{d} V_{\mathrm{a}}}{\mathrm{d} r}
$$



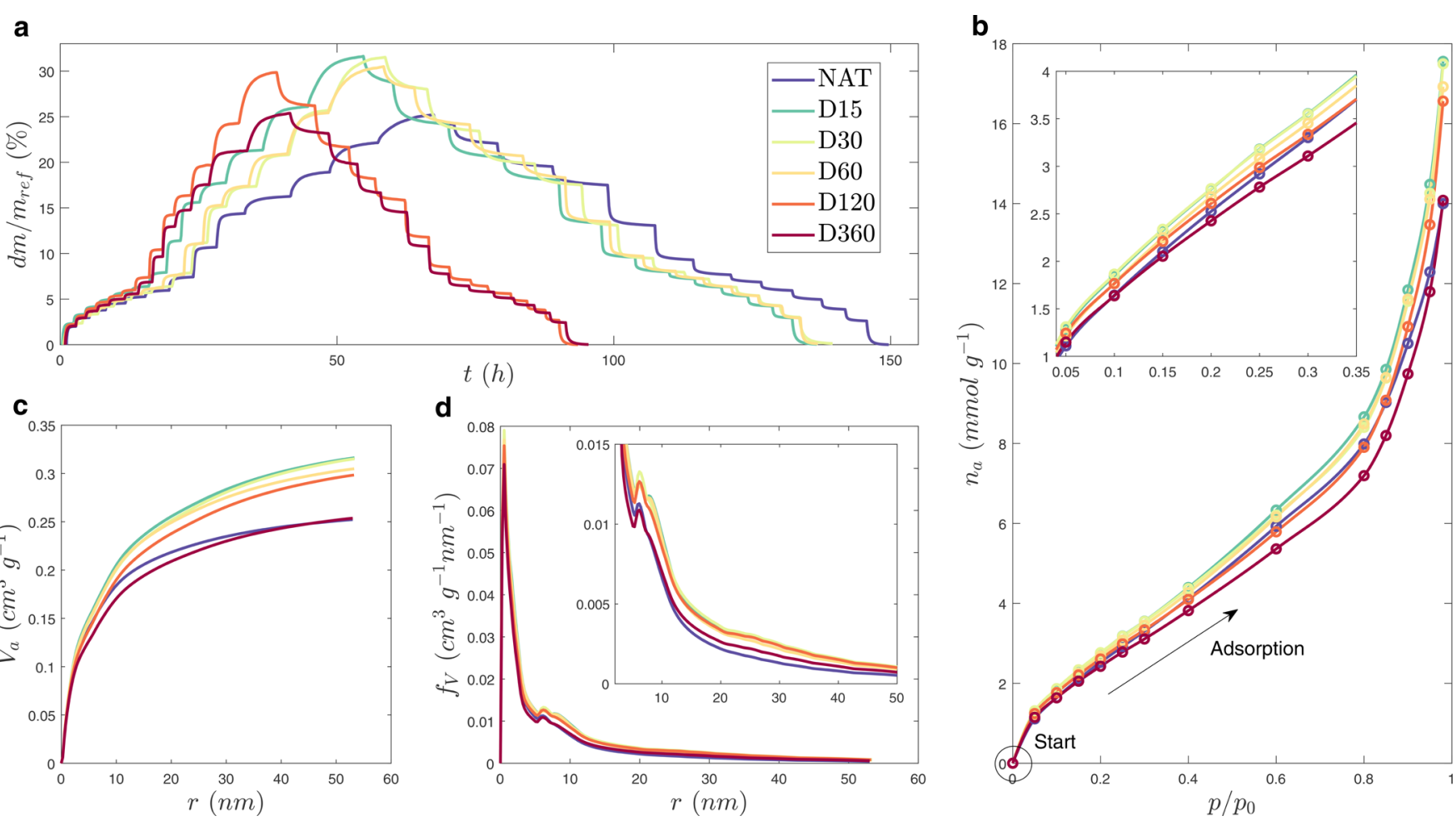

Figure 1. (a) Sorption kinetics. Change in sample mass relative to reference mass $\left(\mathrm{d} m / \mathrm{m}_{\mathrm{ref}}\right)$ versus time $t$ during adsorption and desorption for respective target $p / p_{0}$. (b) Adsorption isotherms. Amount of water vapor adsorbed $\left(n_{\mathrm{a}}\right)$ in function of partial pressure $\left(p / p_{0}\right)$, including zoom into the range $p / p_{0}=0.05-0.25$. Markers represent data points, and lines represent isotherm fits. (c) Cumulative adsorbed water volume $\left(V_{\mathrm{a}}\right)$ in theoretical pores of cylinder radius $r$ from adsorption curves. (d) Pore volume distribution $\left(f_{\mathrm{V}}\right)$, including zoom into the mesopore range $(r=2-$ $50 \mathrm{~nm})$.

for cylindrical pores of radius $r$. The term $\mathrm{d} V_{\mathrm{a}} \mathrm{d} r^{-1}$ can be calculated by numerical differentiation from fitted $V_{\mathrm{a}}\left(n_{\mathrm{a}}\right)$ versus $r\left(n_{\mathrm{a}}, p / p_{0}\right)$ curves.

It has to be noted that the mesopore range $(2<2 r<50 \mathrm{~nm})$ approximately corresponds to the partial water vapor pressure range of $0.4<p / p_{0}<0.95$ as shown in the Supporting Information (Figure S1). This range, based on the current understanding of sorption mechanisms, reasonably represents and limits the validity of the derived PSD for lignocellulosic materials. Below, the sorption mechanism remains uncertain, and above, the exact experimental generation of water vapor $p /$ $p_{0}$ becomes questionable.

\section{RESULTS AND DISCUSSION}

Figure 1a shows the sorption kinetics of native (NAT), partially (D15-D120), and fully delignified wood (D360). Fully delignified wood and D120 exhibit the fastest sorption behavior, while native wood shows the slowest sorption behavior. The partially delignified samples D15, D30, and D60 show a slightly faster sorption behavior than NAT while being significantly slower than D120 and D360. The most distinct changes in sample sorption kinetics are seen after $15 \mathrm{~min}$ and between 60 and $120 \mathrm{~min}$ of delignification. As the sorption kinetics in the cell wall is influenced by diffusion processes through pores of different sizes, the change in sorption kinetics can be explained by a structural change that is affecting the diffusion path. After partial delignification, a certain amount of matrix remains to support a porous scaffold structure, while the removed material builds the pore space. Additionally, changes in structure on the tissue scale (e.g., the removal of the middle lamella between wood cells) could equally influence sorption kinetics.

The adsorption isotherm in terms of adsorbed number of molecules $\left(n_{\mathrm{a}}\right)$, obtained by plotting the sorption equilibrium points from Figure 1a, is shown in Figure 1b. By comparing the NAT and D360 curves, it can be seen that a larger water amount is adsorbed on the NAT sample until $p / p_{0}=0.98$. Samples D15, D30, and D60 adsorb more water than native wood, while D120 adsorbs the same amount until $p / p_{0}=0.85$. As above, more water is adsorbed by the D120 sample. Partial delignification up to $60 \mathrm{~min}$ seems to expose more sorption sites and creates pore space for increased adsorption. However, after $120 \mathrm{~min}$ of delignification, the adsorption capacity decreases, and the fully delignified sample shows the lowest adsorption capacity over the whole $p / p_{0}$ range. A possible explanation for this behavior is a collapse of the delignified wood cell wall after drying due to the absence of a supporting matrix. Scanning desorption curves and the hysteresis are shown in the Supporting Information (Figure S1). For lignocellulosic materials, the meaning and interpretation of the scanning desorption isotherm, especially the hysteresis effect, is currently the subject of debate. ${ }^{4-51}$ For this reason, PSDs derived from the adsorption curves are discussed in the following.

From the amount of water volume $\left(V_{\mathrm{a}}\right)$ that can be incorporated in the scaffold of the cell wall (Figure 1c), it is visible that partial delignification creates an increase in porosity compared to native wood. The adsorbed water volume is significantly higher after condensation in pores with a larger radius than $10 \mathrm{~nm}$. The number of pores present after water adsorption (i.e., the PSD curves) is shown in Figure 1d. 
According to the curves, the majority of the pores of all samples are below a radius of $2 \mathrm{~nm}$, while a smaller number possess radii up to $50 \mathrm{~nm}$. The amount of pores between 2 and $20 \mathrm{~nm}$ is responsible for the major water volume adsorption (Figure 1c), and samples D15 to D120 possess a larger amount of such pores in comparison to the NAT and D360 samples.

To verify the hypothesized collapse of delignified wood upon drying, we additionally investigated the never-dried state of native and fully delignified wood by measuring true desorption isotherms, ${ }^{52}$ starting from the fully water-saturated state. Fully delignified wood shows a higher water content above $p / p_{0}=0.9$ compared to native wood, which can be seen in Figure 2a. Upon reducing the partial pressure, the water content in delignified wood is decreased more abruptly

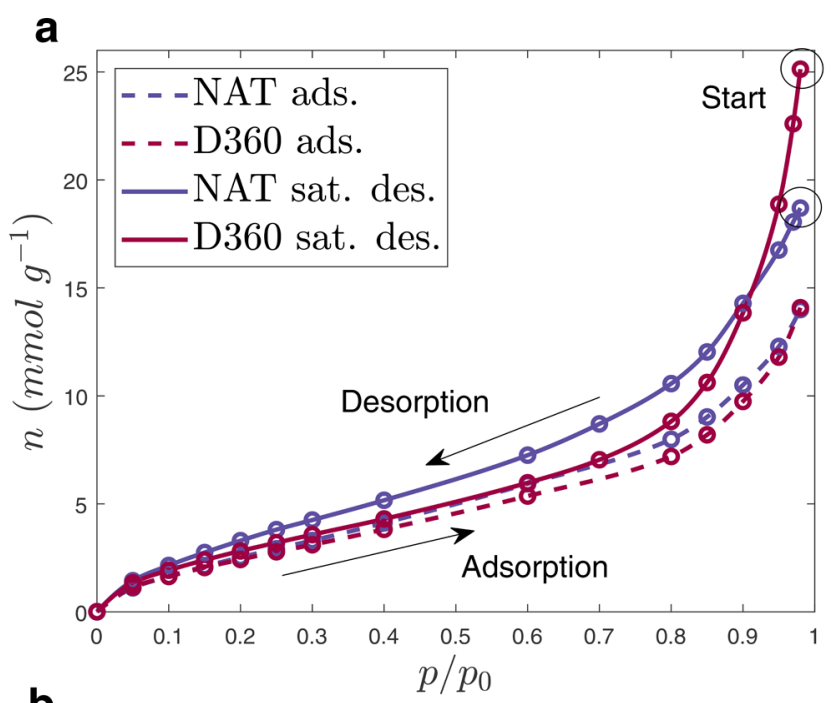

b
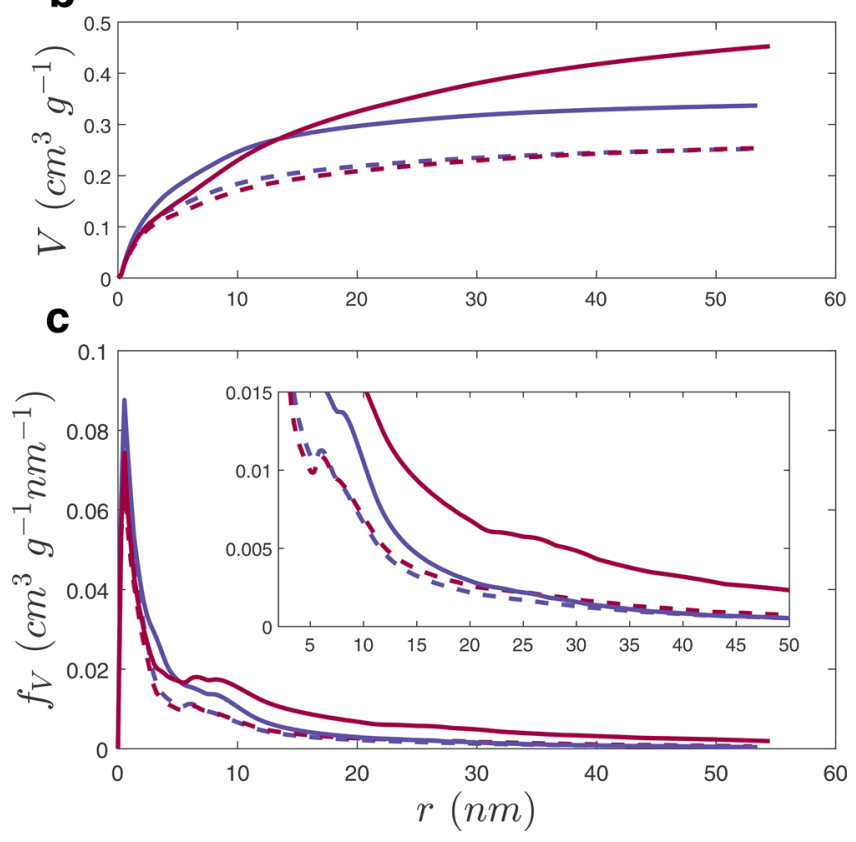

Figure 2. (a) True desorption isotherms starting from the watersaturated state for samples NAT and D360 along adsorption isotherms. Circles represent data points, and lines represent fit curves. (b) Cumulative adsorbed water volume $\left(V_{\mathrm{a}}\right)$ in theoretical pores of cylinder radius $r$ from true desorption curves of samples NAT and D360. (c) Pore volume distribution $\left(f_{\mathrm{V}}\right)$, including zoom into the range $r=2-50 \mathrm{~nm}$. compared to native wood, resulting in an intercept point of the curves at $p / p_{0}=0.9$, which indicates a collapse. Furthermore, at lower $p / p_{0}$, delignified wood shows a lower water content than native wood, as observed already in the adsorption isotherms in Figure 1b. The derived PSDs from the saturated desorption, which are shown in Figure 2c and Figure S4.2, further support the hypothesis. The difference in porosity of the water-saturated state compared to the dry state is significantly more pronounced for delignified wood than for native wood. Compared to native wood, a larger amount of mesopores is present in the water-saturated delignified sample. Such an open porosity in the wet state could be beneficial when it comes to functionalization of the cellulose scaffold, as the higher permeability eases the in situ formation of, for example, polymers or minerals.

As mentioned before, the PSD curves can only be interpreted in the mesopore range, where capillary condensation is assumed to be far more relevant than localized adsorption. The supposedly nonporous structure below a pore width of $2 \mathrm{~nm}$ can be assessed by techniques revealing the number of sorption sites. In theory, these are equivalent to the available amount of hydroxyl groups. Figure 3 displays the total

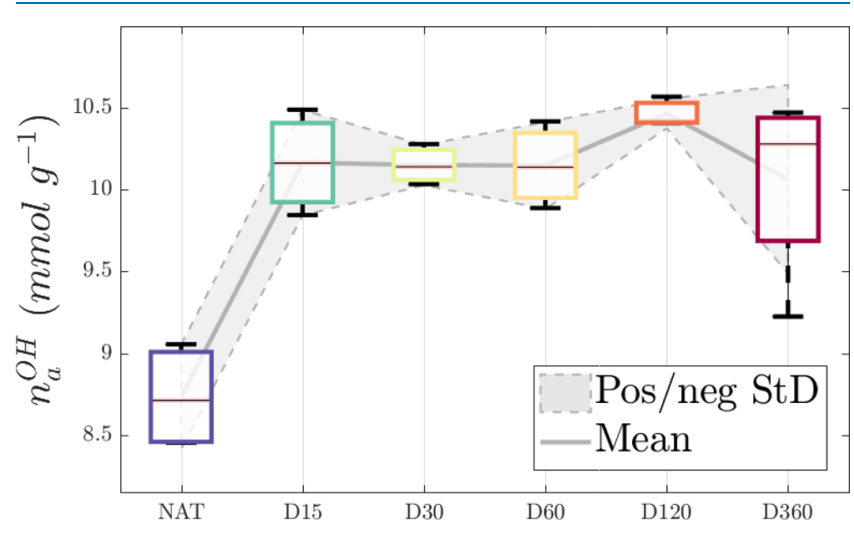

Figure 3. Number of available $\mathrm{OH}$ groups by deuteration with $\mathrm{D}_{2} \mathrm{O}$. Statistics for $n=4$ measurements.

number of available $\mathrm{OH}$ groups obtained by sample deuteration using heavy water. Partially delignified wood shows values in between 10 and $10.5 \mathrm{mmol} \mathrm{g}^{-1}$, while native wood shows a lower accessibility between 8.5 and $9 \mathrm{mmol} \mathrm{g}^{-1}$, which is in agreement with literature values. ${ }^{28,29}$ These changes can be either attributed to structural or chemical changes upon delignifification or a combination thereof. Lignin, hemicelluloses, and cellulose possess different amounts of $\mathrm{OH}$ groups. Thus, the matrix material removal cannot be exclusively correlated with structural changes in terms of $\mathrm{OH}$ accessibility. Furthermore, the cellulose crystallinity may have been affected by delignification, ${ }^{53}$ which could further influence the $\mathrm{OH}$ accessibility. In addition, it remains unclear whether the amount of measured accessible hydroxyls can be correlated with the amount of water adsorbed. If this was the case, only the amount of water adsorbed above $p / p_{0}=0.9$ (at $n_{\mathrm{a}}=n_{\mathrm{a}}^{\mathrm{OH}}$ ) could be attributed to capillary condensation, which would be physically untrue given the material is porous (Figure $\mathrm{S} 1$ ). This suggests that the amount of deuterated $\mathrm{OH}$ groups is higher than the amount of local sorption sites interacting with water.

Studies of porosity of the dried native and delignified wood cell wall using $\mathrm{N}_{2}$ and $\mathrm{CO}_{2}$ adsorption have been conducted in 
previous studies. ${ }^{54-56}$ An increase in porosity upon delignification is reported by $\mathrm{Fu}$ et al. ${ }^{10}$ In addition, the structural collapse at the dry state and the open porous system for the water-saturated fully delignified state, as measured for wood in this study, was also reported for pulp ${ }^{7,57}$ and by means of different characterization techniques. $\mathrm{N}_{2}$ adsorption measurements on wood-derived pulp fibers reveal a collapsed porous structure after drying, ${ }^{58,59}$ and by using solvent exchange, the open porous structure was preserved. ${ }^{24,60}$ The specific surface area found by water vapor adsorption in the present study is compared to literature values in Table $S 1$, in accordance with the results.

The water vapor adsorption data and its processing proved useful for quantitative and qualitative characterization of the structural changes upon delignification of the wood cell wall. The proposed model for derivation of PSDs from water adsorption data builds on multiple assumptions and omits some material-inherent aspects such as the influence of swelling on the pore shape or the $3 \mathrm{D}$ complexity of the pore structure in the wood cell wall. However, a significant key advantage is that the material's structure can be revealed and characterized at the water swollen state. This state is of particular relevance for modification and functionalization treatments of lignocellulosic materials for various material applications.

\section{CONCLUSIONS}

Stepwise delignification of the wood cell wall highly affected its structure in terms of porosity. An increase in porosity is reported with higher delignification times by derivation of PSDs from water adsorption data. At full delignification, the pore system collapses upon drying, and porosity is reduced as cellulose fibrils supposedly get more closely packed than in the native state. However, at a water-saturated state, the fully delignified samples possess a highly mesoporous structure, which was demonstrated by deriving PSDs from true desorption isotherms. This can be utilized to optimize modifications at the cell wall level (e.g., by chemical functionalization) to achieve new emerging cellulose-based materials.

\section{MATERIALS AND METHODS}

5.1. Delignification. Norway spruce (Picea abies) cubes (5 $\times 5 \times 5 \mathrm{~mm}^{3}$ ) consisting exclusively of earlywood were prepared. The wood samples were delignified by using an equal volume mixture of hydrogen peroxide solution (35 wt \%, Acros Organics) and glacial acetic acid (Fisher Chemicals) as described in Frey et al. 2018 and Segmehl et al. 2018.,61 The samples were wrapped in a metal grid to prevent disintegration during the delignification treatment and placed into a beaker on top of a metal grid holder. The samples were soaked in the $\mathrm{HAc} / \mathrm{H}_{2} \mathrm{O}_{2}$ mixture overnight under constant stirring $(150 \mathrm{rpm})$. Then, delignification was conducted at 80 ${ }^{\circ} \mathrm{C}$ for $15,30,60,120$, and $360 \mathrm{~min}$, resulting in partially delignified samples D15, D30, D60, and D120 as well as fully delignified sample D360. The degree of delignification was measured by Fourier transform infrared spectroscopy (Supporting Information S3).

5.2. Sorption Isotherms. Dynamic water vapor adsorption and scanning desorption were measured on native (denoted NAT) and delignified wood samples by an automated sorption balance device (DVS Advantage ET85, Surface Measurment
Systems Ltd.). Measurements were conducted according to material-specific recommendations for good practice. ${ }^{62}$ Samples were cut into fine stripes. Ten milligrams of the stripes (65\% relative humidity, $20{ }^{\circ} \mathrm{C}$ ) were then dried for $6 \mathrm{~h}$ at 60 ${ }^{\circ} \mathrm{C}$ and at a partial water vapor pressure of $p / p_{0}=0$. The samples were then exposed to ascending $p / p_{0}$ steps of $0,0.05$, $0.10,0.15,0.20,0.25,0.30,0.40,0.60,0.80,0.85,0.90,0.95$, and 0.98 for adsorption and then descending in the same manner for desorption at $25^{\circ} \mathrm{C}$. Equilibrium in each step was defined to be reached at a mass change per time $(\mathrm{d} m / \mathrm{d} t)$ of less than $0.0005 \% / \mathrm{min}$ over a $10 \mathrm{~min}$ window or a maximal time of $1000 \mathrm{~min}$ per step. The samples were exposed to a flow rate of $200 \mathrm{sccm}$, and the carrier gas used was $\mathrm{N}_{2}$ of grade 5.0. Additionally, true desorption isotherms for samples NAT and D360 were measured starting in the water-saturated state following Fredriksson and Thybring 2018. ${ }^{52}$

The amount adsorbed $n_{\mathrm{a}}$, in units of mmol adsorbate per gram of adsorbent, is derived from recorded raw data, that is, mass change $\mathrm{d} m$, with $n_{\mathrm{a}}=\mathrm{d} m\left(m_{\mathrm{ref}} \mathrm{M}_{\mathrm{H}_{2} \mathrm{O}}\right)^{-1}$. Analytical isotherm curves $\left(n_{\mathrm{a}}=f\left(p / p_{0}\right)\right)$ were obtained by piecewise polynomial smoothing splines with a perfect goodness of fit to the data points $\left(R^{2}=1\right)$.

5.3. Hydroxyl Accessibility. The samples were prepared in the same manner as the sorption isotherm measurements, and the same drying procedure was applied to obtain the reference mass (dry mass) $m_{\text {ref. }}$ The samples were then exposed to $\mathrm{D}_{2} \mathrm{O}$ vapor at $p / p_{0}=0.95$ and $25{ }^{\circ} \mathrm{C}$ for $9 \mathrm{~h}$. Then, the drying routine was applied again, and the deuterated dry mass $m_{\mathrm{D} \text {, ref }}$ was obtained. $\mathrm{ROH}+\mathrm{D}_{2} \mathrm{O} \rightleftharpoons \rightleftharpoons \mathrm{ROD}+\mathrm{HDO}$ represents the dynamic exchange reaction where the biopolymer is represented by the term $\mathrm{ROH}$ ( $\mathrm{ROD}$ in the deuterated state). To avoid deprotonation during the second drying, $\mathrm{N}_{2}$ of grade 6.0 (traces of $\mathrm{H}_{2} \mathrm{O}<0.5 \mathrm{ppm}$ ) was used as the carrier gas. The number of available $\mathrm{OH}$ groups was calculated as

$$
n_{\mathrm{a}}^{\mathrm{OH}}=\frac{m_{\mathrm{D}, \mathrm{ref}}-m_{\mathrm{ref}}}{m_{\mathrm{ref}}\left(M_{\mathrm{D}}-M_{\mathrm{H}}\right)}
$$

where $M_{\mathrm{D}}$ and $M_{\mathrm{H}}$ are molar masses.

\section{ASSOCIATED CONTENT}

\section{(S) Supporting Information}

The Supporting Information is available free of charge on the ACS Publications website at DOI: 10.1021/acsomega.9b00862.

Images of scanning desorption isotherms, sorption hysteresis, change in Gibbs free energy of adsorption, and mesopore range in terms of partial water vapor pressure; comparison of multilayer sorption (BET) and energetic interaction theories; degree of delignification by Fourier transform infrared spectroscopy; and generation of approximate data-fidelity images of the PSD (PDF)

\section{AUTHOR INFORMATION}

\section{Corresponding Authors}

*E-mail: philippe.groenquist@empa.ch (P.G.).

*E-mail: marionfrey@ethz.ch (M.F.).

ORCID $\odot$

Philippe Grönquist: 0000-0001-8432-1706

Ingo Burgert: 0000-0003-0028-072X 


\section{Author Contributions}

IIP.G. and M.F. contributed equally to this work.

Notes

The authors declare no competing financial interest.

\section{ACKNOWLEDGMENTS}

The authors thank Emil Engelund Thybring for the help and discussion on the dynamic vapor sorption measurements.

\section{REFERENCES}

(1) Ansari, F.; Sjöstedt, A.; Larsson, P. T.; Berglund, L. A.; Wågberg, L. Hierarchical wood cellulose fiber/epoxy biocomposites - Materials design of fiber porosity and nanostructure. Composites. Part A 2015, $74,60-68$.

(2) Frey, M.; Widner, D.; Segmehl, J. S.; Casdorff, K.; Keplinger, T.; Burgert, I. Delignified and Densified Cellulose Bulk Materials with Excellent Tensile Properties for Sustainable Engineering. ACS Appl. Mater. Interfaces 2018, 10, 5030-5037.

(3) Yang, X.; Berthold, F.; Berglund, L. A. Preserving Cellulose Structure: Delignified Wood Fibers for Paper Structures of High Strength and Transparency. Biomacromolecules 2018, 19, 3020-3029.

(4) Song, J.; et al. Processing bulk natural wood into a highperformance structural material. Nature 2018, 554, 224-228.

(5) Jia, C.; Chen, C.; Kuang, Y.; Fu, K.; Wang, Y.; Yao, Y.; Kronthal, S.; Hitz, E.; Song, J.; Xu, F.; Liu, B.; Hu, L. From Wood to Textiles: Top-Down Assembly of Aligned Cellulose Nanofibers. Adv. Mater. 2018, 30, 1801347.

(6) Guan, H.; Cheng, Z.; Wang, X. Highly Compressible Wood Sponges with a Spring-like Lamellar Structure as Effective and Reusable Oil Absorbents. ACS Nano 2018, 12, 10365-10373.

(7) Wang, Q.; Xiao, S.; Shi, S. Q.; Cai, L. Effect of lightdelignification on mechanical, hydrophobic, and thermal properties of high-strength molded fiber materials. Sci. Rep. 2018, 8, 955.

(8) Khakalo, A.; Tanaka, A.; Korpela, A.; Hauru, L. K. J.; Orelma, H. All-Wood Composite Material by Partial Fiber Surface Dissolution with an Ionic Liquid. ACS Sustainable Chem. Eng. 2019, 7, 31953202.

(9) Frey, M.; Biffi, G.; Adobes-Vidal, M.; Zirkelbach, M.; Wang, Y.; Tu, K.; Hirt, A. M.; Masania, K.; Burgert, I.; Keplinger, T. Tunable Wood by Reversible Interlocking and Bioinspired Mechanical Gradients. Adv. Sci. 2019, 1802190.

(10) Fu, Q.; Medina, L.; Li, Y.; Carosio, F.; Hajian, A.; Berglund, L. A. Nanostructured Wood Hybrids for Fire-Retardancy Prepared by Clay Impregnation into the Cell Wall. ACS Appl. Mater. Interfaces 2017, 9, 36154-36163.

(11) Gan, W.; Gao, L.; Xiao, S.; Zhang, W.; Zhan, X.; Li, J. Transparent magnetic wood composites based on immobilizing Fe3O4 nanoparticles into a delignified wood template. J. Mater. Sci. 2017, 52, 3321-3329.

(12) Fu, Q.; Ansari, F.; Zhou, Q.; Berglund, L. A. Wood Nanotechnology for Strong, Mesoporous, and Hydrophobic Biocomposites for Selective Separation of Oil/Water Mixtures. ACS Nano 2018, 12, 2222-2230.

(13) Yano, H.; Hirose, A.; Collins, P. J.; Yazaki, Y. Effects of the removal of matrix substances as a pretreatment in the production of high strength resin impregnated wood based materials. J. Mater. Sci. Lett. 2001, 20, 1125-1126.

(14) Keplinger, T.; Wang, X.; Burgert, I. Nanofibrillated cellulose composites and wood derived scaffolds for functional materials. $J$. Mater. Chem. A 2019, 7, 2981-2992.

(15) Thybring, E. E.; Kymäläinen, M.; Rautkari, L. Experimental techniques for characterising water in wood covering the range from dry to fully water-saturated. Wood Sci. Technol. 2018, 52, 297-329.

(16) Ding, W.-D.; Koubaa, A.; Chaala, A.; Belem, T.; Krause, C. Relationship between wood porosity, wood density and methyl methacrylate impregnation rate. Wood Mater. Sci. Eng. 2008, 3, 6270.
(17) Vitas, S.; Segmehl, J. S.; Burgert, I.; Cabane, E. Porosity and Pore Size Distribution of Native and Delignified Beech Wood Determined by Mercury Intrusion Porosimetry. Materials 2019, 12, 416.

(18) Driemeier, C.; Mendes, F. M.; Oliveira, M. M. Dynamic vapor sorption and thermoporometry to probe water in celluloses. Cellulose 2012, 19, 1051-1063.

(19) Kohler, R.; Dück, R.; Ausperger, B.; Alex, R. A numeric model for the kinetics of water vapor sorption on cellulosic reinforcement fibers. Compos. Interfaces 2003, 10, 255-276.

(20) Hill, C. A. S.; Norton, A.; Newman, G. The water vapor sorption behavior of natural fibers. J. Appl. Polym. Sci. 2009, 112, $1524-1537$.

(21) Ganser, C.; Kreiml, P.; Morak, R.; Weber, F.; Paris, O.; Schennach, R.; Teichert, C. The effects of water uptake on mechanical properties of viscose fibers. Cellulose 2015, 22, 2777-2786.

(22) Kulasinski, K.; Guyer, R.; Derome, D.; Carmeliet, J. Water Adsorption in Wood Microfibril-Hemicellulose System: Role of the Crystalline-Amorphous Interface. Biomacromolecules 2015, 16, 2972-2978.

(23) Yang, T.; Ma, E.; Cao, J. Effects of lignin in wood on moisture sorption and hygroexpansion tested under dynamic conditions. Holzforschung 2018, 72, 943-950.

(24) Lovikka, V. A.; Rautkari, L.; Maloney, T. C. Changes in the hygroscopic behavior of cellulose due to variations in relative humidity. Cellulose 2018, 25, 87-104.

(25) Lindh, E. L.; Bergenstråhle-Wohlert, M.; Terenzi, C.; Salmén, L.; Furó, I. Nonexchanging hydroxyl groups on the surface of cellulose fibrils: The role of interaction with water. Carbohydr. Res. 2016, 434, $136-142$.

(26) Altgen, M.; Willems, W.; Hosseinpourpia, R.; Rautkari, L. Hydroxyl accessibility and dimensional changes of Scots pine sapwood affected by alterations in the cell wall ultrastructure during heattreatment. Polym. Degrad. Stab. 2018, 152, 244-252.

(27) Rautkari, L.; Hill, C. A.; Curling, S.; Jalaludin, Z.; Ormondroyd, G. What is the role of the accessibility of wood hydroxyl groups in controlling moisture content? J. Mater. Sci. 2013, 48, 6352-6356.

(28) Tarmian, A.; Burgert, I.; Thybring, E. E. Hydroxyl accessibility in wood by deuterium exchange and ATR-FTIR spectroscopy: methodological uncertainties. Wood Sci. Technol. 2017, 51, 845-853.

(29) Thybring, E. E.; Thygesen, L. G.; Burgert, I. Hydroxyl accessibility in wood cell walls as affected by drying and re-wetting procedures. Cellulose 2017, 24, 2375-2384.

(30) Bertaud, F.; Holmbom, B. Chemical composition of earlywood and latewood in Norway spruce heartwood, sapwood and transition zone wood. Wood Sci. Technol. 2004, 38, 245-256.

(31) Fahlén, J.; Salmén, L. Pore and Matrix Distribution in the Fiber Wall Revealed by Atomic Force Microscopy and Image Analysis. Biomacromolecules 2005, 6, 433-438.

(32) Altaner, C. M.; Jarvis, M. C. Modelling polymer interactions of the 'molecular Velcro' type in wood under mechanical stress. J. Theor. Biol. 2008, 253, 434-445.

(33) Fernandes, A. N.; Thomas, L. H.; Altaner, C. M.; Callow, P.; Forsyth, V. T.; Apperley, D. C.; Kennedy, C. J.; Jarvis, M. C. Nanostructure of cellulose microfibrils in spruce wood. Proc. Natl. Acad. Sci. 2011, 108, E1195-E1203.

(34) Bertinetti, L.; Fratzl, P.; Zemb, T. Chemical, colloidal and mechanical contributions to the state of water in wood cell walls. New J. Phys. 2016, 18, No. 083048.

(35) Ek, M.; Gellerstedt, G.; Henriksson, G. Paper Chemistry and Technology; Walter de Gruyter, 2009; p 45.

(36) Engelund, E. T.; Thygesen, L. G.; Hoffmeyer, P. Water sorption in wood and modified wood at high values of relative humidity. Part 2: Appendix. Theoretical assessment of the amount of capillary water in wood microvoids. Holzforschung 2010, 64, 325-330.

(37) Engelund, E. T.; Thygesen, L. G.; Svensson, S.; Hill, C. A. S. A critical discussion of the physics of wood-water interactions. Wood Sci. Technol. 2013, 47, 141-161. 
(38) Willems, W. Hygroscopic wood moisture: single and dimerized water molecules at hydroxyl-pair sites? Wood Sci. Technol. 2018, 52, 777-791.

(39) Zelinka, S. L.; Glass, S. V.; Thybring, E. E. Myth versus reality: Do parabolic sorption isotherm models reflect actual wood-water thermodynamics? Wood Sci. Technol. 2018, 52, 1701-1706.

(40) Liu, Y. Is the Free Energy Change of Adsorption Correctly Calculated? J. Chem. Eng. Data 2009, 54, 1981-1985.

(41) Anastopoulos, I.; Kyzas, G. Z. Are the thermodynamic parameters correctly estimated in liquid-phase adsorption phenomena? J. Mol. Liq. 2016, 218, 174-185.

(42) Hosseinpourpia, R.; Adamopoulos, S.; Holstein, N.; Mai, C. Dynamic vapour sorption and water-related properties of thermally modified Scots pine (Pinus sylvestris L.) wood pre-treated with proton acid. Polym. Degrad. Stab. 2017, 138, 161-168.

(43) Zauer, M.; Prinz, C.; Adolphs, J.; Emmerling, F.; Wagenführ, A. Sorption surfaces and energies of untreated and thermally modified wood evaluated by means of excess surface work (ESW). Wood Sci. Technol. 2018, 52, 957-969.

(44) Adolphs, J. Thermodynamics and Modeling of Sorption Isotherms. Chem. Ing. Tech. 2016, 88, 274-281.

(45) Georgi, N.; Kolesnikov, A.; Uhlig, H.; Möllmer, J.; Rückriem, M.; Schreiber, A.; Adolphs, J.; Enke, D.; Gläser, R. Characterization of Porous Silica Materials with Water at Ambient Conditions. Calculating the Pore Size Distribution from the Excess Surface Work Disjoining Pressure Model. Chem. Ing. Tech. 2017, 89, 16791685.

(46) Thommes, M.; Kaneko, K.; Neimark, A. V.; Olivier, J. P.; Rodriguez-Reinoso, F.; Rouquerol, J.; Sing, K. S. Physisorption of gases, with special reference to the evaluation of surface area and pore size distribution (IUPAC Technical Report). Pure Appl. Chem. 2015, $87,1051-1069$

(47) Shkol'nikov, E. I.; Sidorova, E. V. Analytical equation for calculating the pore size distribution from adsorption data. Dokl. Phys. Chem. 2007, 412, 4-7.

(48) Shi, J.; Avramidis, S. Water sorption hysteresis in wood: I review and experimental patterns - geometric characteristics of scanning curves. Holzforschung 2017, 71, 307-316.

(49) Chen, M.; Coasne, B.; Guyer, R.; Derome, D.; Carmeliet, J. Role of hydrogen bonding in hysteresis observed in sorption-induced swelling of soft nanoporous polymers. Nat. Commun. 2018, 9, 3507.

(50) Salmén, L.; Larsson, P. A. On the origin of sorption hysteresis in cellulosic materials. Carbohydr. Polym. 2018, 182, 15-20.

(51) Rémond, R.; Almeida, G.; Perré, P. The gripped-box model: A simple and robust formulation of sorption hysteresis for lignocellulosic materials. Constr. Build. Mater. 2018, 170, 716-724.

(52) Fredriksson, M.; Thybring, E. E. Scanning or desorption isotherms? Characterising sorption hysteresis of wood. Cellulose 2018, 25, 4477-4485.

(53) Agarwal, U. P.; Ralph, S. A.; Reiner, R. S.; Hunt, C. G.; Baez, C.; Ibach, R.; Hirth, K. C. Production of high lignin-containing and lignin-free cellulose nanocrystals from wood. Cellulose 2018, 25, 5791-5805.

(54) Nakatani, T.; Ishimaru, Y.; Iida, I.; Furuta, Y. Micropore structure of wood: Change in micropore structure accompanied by delignification. J. Wood Sci. 2008, 54, 252-255.

(55) Kojiro, K.; Miki, T.; Sugimoto, H.; Nakajima, M.; Kanayama, K. Micropores and mesopores in the cell wall of dry wood. J. Wood Sci. 2010, 56, 107-111.

(56) Larsson, P. T.; Svensson, A.; Wågberg, L. A new, robust method for measuring average fibre wall pore sizes in cellulose I rich plant fibre walls. Cellulose 2013, 20, 623-631.

(57) Svensson, A.; Larsson, P. T.; Salazar-Alvarez, G.; Wågberg, L. Preparation of dry ultra-porous cellulosic fibres: Characterization and possible initial uses. Carbohydr. Polym. 2013, 92, 775-783.

(58) Stone, J. E.; Scallan, A. M. Effect of component removal upon the porous structure of the cell wall of wood. J. Polym. Sci., Part C: Polym. Symp. 1965, 11, 13-25.
(59) Park, S.; Venditti, R. A.; Jameel, H.; Pawlak, J. J. Changes in pore size distribution during the drying of cellulose fibers as measured by differential scanning calorimetry. Carbohydr. Polym. 2006, 66, 97103.

(60) Lovikka, V. A.; Khanjani, P.; Väisänen, S.; Vuorinen, T.; Maloney, T. C. Porosity of wood pulp fibers in the wet and highly open dry state. Microporous Mesoporous Mater. 2016, 234, 326-335.

(61) Segmehl, J.; Studer, V.; Keplinger, T.; Burgert, I. Characterization of Wood Derived Hierarchical Cellulose Scaffolds for Multifunctional Applications. Materials 2018, 11, 517.

(62) Glass, S. V.; Boardman, C. R.; Thybring, E. E.; Zelinka, S. L. Quantifying and reducing errors in equilibrium moisture content measurements with dynamic vapor sorption (DVS) experiments. Wood Sci. Technol. 2018, 52, 909-927. 